\title{
Optimal Income Taxation and Job Choice *
}

\author{
Robin Boadway \\ Queen's University, Kingston, Ontario, Canada, K7L 3N6 \\ boadwayr@econ.queensu.ca \\ Zhen Song \\ CEMA \& CIAS, Central University of Finance and Economics, Beijing, China, 100081 \\ songzhen@cufe.edu.cn \\ Jean-François Tremblay \\ University of Ottawa, Ottawa, Ontario, Canada, K1N 6N5 \\ Jean-Francois.Tremblay@uottawa.ca
}

\begin{abstract}
This paper studies optimal income taxation when different job types exist for workers of different skills. Each job type has some feasible range of incomes from which workers choose by varying labour supply. Workers are more productive than others in the jobs that suit them best. The model combines features of the classic optimal tax literature with labour variability along the intensive margin with the extensive-margin approach where workers make discrete job choices and/or participation decisions. We find that first-best maximin utility can be achieved in the second-best, and marginal tax rates below the top can be negative or zero.
\end{abstract}

Keywords: optimal income tax, job choice, intensive margin, extensive margin JEL classification: H21, H23, H24

* We are grateful to Laurent Simula for careful comments on an earlier version of this paper. Research support was provided by the Social Sciences and Humanities Research Council of Canada. 


\section{Introduction}

In models of optimal income taxation, the focus has been largely on the labour supply side. The nature of jobs offered has not been explicitly modeled. Two extreme cases have been studied. The standard intensive-margin approach, following Mirrlees (1971), effectively assumes that workers of different skills are perfect substitutes in production. The amounts of effective labour per hour of work reflects skills, and workers receive a fixed wage rate equal to their skill. In extensive-margin models, jobs are offered that are suited for each type of skill, and that pay a fixed wage for a given amount of effort (Diamond 1980). In some versions of the extensive-margin model, workers of a given skill can choose the job suited for a less-skilled worker, but if they do they receive the same fixed wage (Saez 2002).

These two approaches have led to important insights into the structure of optimal income taxes and how they are affected by the nature of labour supply decisions, but they have set aside characteristics of jobs that are potentially relevant for income tax design. For one thing, workers have different job-specific skills, which may make them more productive than others in the job that suits them best. Given the division of labour in a modern economy and the specialization that entails, a worker tends to perform a narrow set of tasks within a work unit. Each set of tasks requires a corresponding set of special skills that workers possess in different degrees, such as innate ability, education and training, and work experience. Workers will have different comparative advantages at jobs requiring different sets of skills. Moreover, some workers may have an absolute advantage over workers with different skills at those jobs that suit them best. This may be the case even if some jobs require higher skills than others in some aggregate sense. Workers who are most suited for higher skill jobs may be less productive in jobs requiring lesser skills.

For another thing, the assumption used in extensive-margin models that hours worked and incomes are absolutely fixed seems a bit restrictive, while that used in intensive-margin models that workers can choose any income by freely varying their labour supply may also be restrictive. The spirit of extensive-margin models can be captured in less inflexible ways, while at the same time offering workers some flexibility of effort, by assuming that different jobs allow different income ranges. This possibility seems clear in comparing high-income and low-income jobs. One expects that these will differ at least in their lower income bound 
and perhaps also in their upper bound. Even between jobs that belong to a similar broad income category, income ranges available from them may still differ. For example, sales jobs in agency/brokerage firms can be said to belong to the same broad income category but often offer different minimum, guaranteed salaries. In this case, the income ranges of different jobs differ at least in their lower bounds. More generally, it is reasonable to suppose that some minimum discrete quantity of work-time per day is necessary just to settle into the required routine in a given job, and beyond some maximum, concentration or strength may deteriorate significantly.

In this paper, we explore the consequences for optimal nonlinear income taxation of these two features of jobs: the absolute advantage workers have in jobs suited to them, and the fact that different jobs may have different feasible income ranges. These features are incorporated in a stylized way into the discrete-types model of Stiglitz (1982) and Guesnerie and Roberts (1982). Workers are assumed to differ in a single characteristic, which we refer to as skill. There are different jobs in the economy, each one most suited for a given skill level, and at least the lower limits of the income ranges of the jobs differ. Workers obtain the highest wage rate in the job matching their skill. They can choose other jobs, but will earn a lower wage. As well, each job pays the highest wage to the worker with the matching skill, and jobs requiring higher skill levels pay higher wage rates. Note the important feature that a worker with a higher skill level who chooses a job requiring lower skills will earn a lower wage rate than the worker with the matching skills.

We first analyze a basic model with two worker types, high- and low-skilled, and two job types, also high- and low-skilled. Workers in this model make two sequential decisions. They choose one of the jobs, and then they decide how much labour to supply, subject to the income bounds associated with the job. The government is assumed to have nonnegative aversion to inequality, so it redistributes from the higher skilled to the lower skilled workers. We then extend the model to allow for more worker- and job-types, albeit restricting their numbers to be the same.

The results in our basic model contrast sharply to those in the standard MirrleesStiglitz model. The marginal tax rate for workers below the top will be negative if the incentive constraint is binding and if both workers are in the job that matches their skills, 
unless one of the income bounds is binding. The marginal tax rate at the top will be zero unless an income constraint is binding at the upper bound. With maximin social preferences, first-best levels of utility can be achieved through nonlinear income taxation in the second-best, and that may be true with less redistributive social welfare functions as well. With utilitarian social preferences, outcomes in both the first- and the secondbest involve more redistribution than under maximin preferences. Moreover, a higher government revenue requirement and a lower redistributive preference tend to result in the low-skilled worker working at the high-skilled job, which does not match his skill level. When we extend the model to multiple types, we find that negative marginal tax rates for workers below the top again obtain under similar conditions as in the basic model.

The intuition for the possibility of a negative marginal tax rate below the top is straightforward. A higher skilled worker mimicking a lower skilled worker may have to choose the lower skilled job. If so, the mimicking high skilled worker will be earning a lower wage than the lower skilled worker. This effectively makes the incentive constraint upwardbinding. Relaxing the incentive constraint to facilitate redistribution involves distorting the labour supply of the low skilled worker upwards, which requires a negative marginal tax rate.

This paper is related to several strands of literature. The seminal paper in the optimal income tax literature is Mirrlees (1971), who assumes workers are drawn from a continuous skill distribution. (See also Tuomala (1990) and Ebert (1992) for useful elaborations.) We follow the discrete skill-type case, proposed initially by Stern (1982) and Stiglitz (1982) for the two-type case, and Guesnerie and Seade (1982) for multiple types, and pursued subsequently by Weymark (1986), Homburg (2001) and Hellwig (2007), among others.

Negative marginal tax rates have been shown to arise in various intensive-margin settings. They can result from general equilibrium effects as in Stiglitz (1982), who argued that by stimulating high-skilled labour supply, a negative marginal tax rate at the top can improve relative wages for the low-skilled. Negative marginal tax rates can also arise if individuals differ both in skills and in preferences for leisure, so upward-binding incentive constraints apply if the government wants to redistribute from those with high skills and preferences for leisure to those with low skills and preferences for leisure (Boadway et al 
2000; Choné and Laroque 2010). Beaudry, Blackorby and Szalay (2009) assume workers have differing productivities in market and non-market activities, and show that when the government cannot observe non-market activities, marginal tax rates at the bottom will be negative. Krause (2009) obtains the possibility of negative marginal tax rates in a two-period model where second-period wages depend on first-period labour supply, via a learning-by-doing effect. It may be optimal to subsidize low-skilled labour supply in the first period, since this will increase the low-skilled wage rate in the second period which both improves redistribution and weakens the second-period incentive constraint.

The rest of the paper is organized as follows. Section 2 sets up the model by introducing job-specific wage rates and job-specific income ranges into a standard, discrete-type model of optimal income taxation. Section 3 analyzes this model in the 2-worker-2-job basic case. Section 4 generalizes the basic model by allowing for more worker types and more jobs. In the concluding section, we briefly discuss how the model could be extended to include a fixed cost of participation as well as job-specific disutility-of-work.

\section{Basic Setting}

The model combines features of the classic optimal income tax literature with labour variability along the intensive margin (Mirrlees 1971; Stiglitz 1982) with those of the extensive-margin approach where workers make discrete job choice and/or participation decisions (Diamond 1980; Saez 2002). There are a given number of types of jobs, indexed by the superscript $j=1, \cdots, N$, each matching a given level of skills. By convention, job $j$ matches more productive skills than job $j-1$, and offers a higher wage rate if the job is filled with the most suitable worker. There is a population of workers who differ in their aptitude and ability to fill jobs of different skills. For simplicity, we assume that there are also $N$ worker types, which will be indexed by a subscript $i=1, \cdots, N$. Workers can in principle fill any type of job. However, they will earn the highest wage rate if they choose the job for which they are most suited, which by convention is the job for which $j=i$. The wage rates reflect worker productivities and are fixed for a given type of worker in a given job. Let $w_{i}^{j}$ be the wage of a type- $i$ worker in a type- $j$ job. The pattern of wage rates satisfies the following assumption: 
Assumption 1. Wage rates satisfy:

(i) $w_{j}^{j}>w_{j}^{k}$ for all $k \neq j$

(ii) $w_{j}^{j}>w_{k}^{j}$ for all $k \neq j$

(iii) $w_{j}^{j}>w_{j-1}^{j-1}$

Assumption 1(i) states that a worker makes the highest wage in the job for which he is best suited. It applies whether a worker of given skill (worker $j$, say) chooses a job suited for a lower-skilled worker (job $k$, with $k<j$ ) or for a higher-skilled worker (job $k$, with $k>j$ ). Assumption 1(ii) says that a worker most suited for any job will earn a higher wage in that job than any other type of worker (including those suited for higher skilled jobs). Assumption 1(iii) indicates that workers of higher skills earn higher wages than those of lower skills if both are employed in their most suited job. These assumptions do not fully characterize all possible wage patterns, but are the most relevant ones for our purposes. ${ }^{1}$

Workers can choose jobs at will, and can change jobs without cost. They can also choose how much labour to supply, which is determined both by their preferences and by some restrictions we impose below on permissible earnings in each type of job. (They may also choose whether to participate in the labour market, but we defer consideration of that until later.) All workers share the same preferences, represented by the utility function $U(C, L)$, where $C$ is aggregate consumption and $L$ is labour supply. We assume that $U(C, L)$ is increasing in $C$ and decreasing in $L$, and is strictly concave. Moreover, leisure is assumed to be non-inferior, and leisure and consumption are gross substitutes. Utility does not depend directly on the type of job, but the wage rate does.

Let $Y_{i}^{j} \equiv w_{i}^{j} L_{i}^{j}$ be income of a type- $i$ worker in a type- $j$ job. Following standard practice, it is useful to rewrite utility in terms of consumption and income as follows:

$$
V_{i}^{j}\left(C_{i}^{j}, Y_{i}^{j}\right) \equiv U\left(C_{i}^{j}, \frac{Y_{i}^{j}}{w_{i}^{j}}\right)
$$

1 For example, these assumptions do not fully specify the relation between wages of workers who are not in jobs for which they are best suited (i.e., $w_{j+1}^{j} \gtreqless w_{j}^{j+1}$ ). In our base case, we consider two types of jobs, $j=1,2$, and two types of workers $i=1,2$, where worker 2 is highskilled and worker 1 is low-skilled. Assumption 1 implies that either $w_{2}^{2}>w_{1}^{1}>w_{1}^{2}>w_{2}^{1}$ or $w_{2}^{2}>w_{1}^{1}>w_{2}^{1}>w_{1}^{2}$. 
If $j=i$, the worker is working in the most-suited job. A worker of a given type could mimic the consumption-income bundle of a different type of worker. For a worker of type $i$ who mimics a worker of type $k$ when the latter is in a type- $k$ job, utility will be written $\widehat{V}_{i}^{k}\left(C_{k}^{k}, Y_{k}^{k} / w_{i}^{k}\right)$. Note that this expression assumes that mimicking involves choosing the job of the other type, though that need not be the case depending on the permissible levels of income that can be earned in each job, to which we now turn.

We assume that for each job-type, income is restricted to be within a given range. Let $\bar{Y}^{j}$ and $\underline{Y}^{j}$ be the upper and lower limits of income that can be earned in job $j$. We generally assume that $\bar{Y}^{j}>\bar{Y}^{j-1}$ and $\underline{Y}^{j}>\underline{Y}^{j-1}$, so it is possible that the two ranges are disjoint or partially overlap. We consider both cases below, as well as the case where there is no upper bound. We assume that all workers can reach all income levels in jobs that they might be tempted to take. This simplifies the analysis, and can be relaxed to some extent without affecting our main insights. The assumption that feasible incomes are bounded in each job can be viewed as a reasonable generalization of the pure extensivemargin job choice model of Saez (2002), where incomes are completely fixed. It allows us to combine features of the extensive and intensive margins of labour supply, albeit at the cost of keeping track of these constraints. If there were no bounds on incomes, workers would always choose the job-type in which they are most productive.

The assumptions of the basic setting are illustrated in Figure 1, which depicts the preferences for a given type of worker, assumed to be type 2, who chooses among three job-types: one for which he is most suited (type 2), one for a lesser-skilled worker (type 1) and one for a more-skilled worker (type 3). The feasible income ranges for the three jobs are assumed to be disjoint for illustrative purposes. The wage rate paid to the type- 2 worker in job 2 exceeds that in both other jobs, $w_{2}^{2}>w_{2}^{1}, w_{2}^{3}$. This implies that if a worker works in jobs of type 1 or type 3, more effort is required to earn a given level of income, so indifference curves will be steeper for any given income. This is reflected in the three indifference curves shown in the figure in each job. Those labeled $i$ represent the same level of utility in all jobs, indifference curves $i i$ represents a lower level of utility, and those labeled $i$ ii represent an even lower level. If $\bar{Y}^{1}$ is sufficiently close to $\underline{Y}^{2}$, indifference curves in job 1 at $\bar{Y}^{1}$ will be steeper than those in job 2 at $\underline{Y}^{2}$ and vertically higher. Similarly, 
for $\bar{Y}^{2}$ sufficiently close to $\underline{Y}^{3}$, the indifference curves in job 2 will be flatter at $\bar{Y}^{2}$ than those for job 3 at $\underline{Y}^{3}$ and vertically lower. This is the case shown in the figure.

Figure 1 shows two more things. First, in the laissez-faire situation, workers must choose a point on a budget constraint that is at $45^{\circ}$ to the origin. In the circumstances of Figure 1, worker 2 will choose the indifference curve $i$ in job 2, the most-suited job. We assume in what follows that workers always choose their most suited job in the laissezfaire. $^{2}$ Second, the figure shows expansion paths for the worker in jobs 1 and 2 from lump-sum changes in income. Note in particular that such changes will eventually lead to a corner solution at an income bound (unless preferences are quasilinear in consumption so expansion paths are vertical). Thus, for some levels of utility, a worker's indifference curve may have a slope everywhere below unity or above unity in the income range of some job. This will have implications for optimal marginal tax rates below.

Figure 2 allows for both type 1's and type 2's on the same diagram, and considers three types of jobs, 1, 2 and 3, that each of the two workers can choose. Three indifference curves labeled $i$, ii and $i i i$ are shown for the type-1 worker, while those for type-2's are labeled $\boldsymbol{i}$, $\boldsymbol{i i}$ and $\boldsymbol{i i i}$. These curves are drawn on the assumption that worker 1 obtains a lower wage rate in job 3 than in job $2\left(w_{1}^{2}>w_{1}^{3}\right)$, and worker 2 earns a higher wage in job 3 than does worker $1\left(w_{2}^{3}>w_{1}^{3}\right)$. This figure can be used to illustrate some important properties of the model that are relevant for the optimal income tax structure. The first is that if there were only two workers and two jobs, say, jobs 1 and 2, the single-crossing property applies for these disjoint indifference curves. That is, if indifference curves of worker 1 and worker 2 intersect in the range of job 1, these same indifference curves cannot intersect in the income range of job $2 .^{3}$ However, this single-crossing property does not hold more generally. For example, in Figure 2, indifference curves for workers 1 and 2 can intersect in both income ranges 1 and 3 (or in both 2 and 3 ). The second is that the single-crossing

${ }^{2}$ It is possible that workers might choose a job for which they are not best suited in the laissezfaire. This can occur for certain configurations of preferences and feasible income ranges. For simplicity, we assume this case away.

3 To see this, suppose that indifference curves $i$ and $i$ intersect twice, once in income range 1 and again in income range 2. By Assumption 1(ii), the former intersection implies that worker 1 is better off than worker 2, while the latter implies the opposite. This is a contradiction. 
property works in the opposite direction in different income ranges. In the income range of job 1, type 1's have flatter indifference curves than type 2's at an intersection point since they have higher wages. At the same time, at intersections in job 2's income range, type 2's have flatter indifference curves than type 1's for the same reason.

Finally, in the laissez-faire, higher-skilled workers are better off than lower-skilled ones, given that we have assumed that the laissez-faire is not income-constrained. This is illustrated by the points $\ell_{1}$ and $\ell_{2}$ in Figure 2 for the case of workers 1 and 2 when both are assumed to choose points within the feasible income ranges of their preferred jobs. Worker 2 has a higher wage rate than worker 1 , and they are both on $45^{\circ}$ budget lines. As in the standard case, worker 2 is better off than worker 1 . The implication is that a government with non-negative aversion to inequality will want to redistribute from type 2's to type 1's. We now turn to government policy in the simplest case where there are only two types of workers and two types of jobs.

\section{Optimal Income Taxation in the Two-Type Case}

There are two types of workers, $i=1,2$, and two types of jobs, $j=1,2$. For simplicity, assume there is one worker of each type. The government levies a non-linear income tax on workers, or equivalently chooses consumption-income bundles for the two types of workers, to maximize a weighted utilitarian social welfare function, subject to a) the requirement of raising a given level of revenue, b) the workers' incentive constraints, and c) the income bounds associated with each job. The incentive constraints reflect the fact that the government cannot observe worker types, only the income they earn. We also assume the government does not observe the workers' jobs, although in the case where income ranges are distinct this can be inferred. We assume from the outset that the optimum involves a separating equilibrium. It is straightforward to show that this will be optimal unless revenue requirements are so high that both workers pool at the upper bound of the income range of job 2. However, unlike in the laissez-faire and in a first-best allocation, we cannot assume that it is optimal for each type of worker to be in their most-suited job. To allow for different possibilities, we drop the job superscript from consumption-income bundles for the two types for the time being. 
More formally, we write the social welfare function as $\gamma_{1} V_{1}\left(C_{1}, Y_{1}\right)+\gamma_{2} V_{2}\left(C_{2}, Y_{2}\right)$, where $\gamma_{1}$ and $\gamma_{2}$ are the social welfare weights for the low-skilled and high-skilled workers. We assume that $\gamma_{1} \geq \gamma_{2} \geq 0$ given that the government is averse to inequality. Under utilitarianism, we have $\gamma_{1}=\gamma_{2}>0$, while with maximin, $\gamma_{1}>\gamma_{2}=0 .{ }^{4}$ The government maximizes social welfare subject to several constraints. One is the resource or budget constraint, $\left(Y_{1}-C_{1}\right)+\left(Y_{2}-C_{2}\right) \geq K$, where $K \geq 0$ by assumption. Next, there are incentive constraints on the two types of workers, $V_{2}\left(C_{2}, Y_{2}\right) \geq \widehat{V}_{2}\left(C_{1}, Y_{1}\right)$ and $V_{1}\left(C_{1}, Y_{1}\right) \geq$ $\widehat{V}_{1}\left(C_{2}, Y_{2}\right)$, which ensure that each worker prefers his own consumption-income bundle to that of the other worker. Unlike in the standard case, mimicking may require workers changing jobs, for example, when the income ranges are disjoint and workers are in different income ranges in the optimum. Finally, optimal incomes may be constrained by the bounds on income ranges in the two jobs: $\underline{Y}^{j} \leq Y_{i} \leq \bar{Y}^{j}$ for $i, j=1,2$. The specific form these take will depend on whether income ranges are disjoint or overlap. ${ }^{5}$

We focus below on the case where the income ranges of the two job-types are disjoint. The case with overlapping income ranges gives similar results, and details can be found Boadway, Song, and Tremblay (2013).

Let $A_{1} \equiv\left(C_{1}, Y_{1}\right)$ and $A_{2} \equiv\left(C_{2}, Y_{2}\right)$ denote the allocations intended for type-1 and type-2 workers respectively. The income ranges are assumed to be disjoint and noncontiguous, so $\bar{Y}^{1}$ is strictly less than $\underline{Y}^{2} \cdot{ }^{6}$ In principle, both $A_{1}$ and $A_{2}$ can be in either job, so there are four possibilities: (i) $A_{1}$ is in income range 1 and $A_{2}$ is in income range 2, (ii) both $A_{1}$ and $A_{2}$ are in income range 2, (iii) $A_{1}$ is in income range 2 and $A_{2}$ is in income range 1 , and (iv) both $A_{1}$ and $A_{2}$ are in income range 1 . In fact, case (iii) cannot arise

${ }^{4}$ We could instead have used a quasi-concave social welfare function. Using the weighted utilitarian form simplifies the notation slightly without affecting the results.

5 In principle, we should also impose non-negativity constraints on consumption, $C_{i} \geq 0$ for $i=1,2$. These can become binding when the revenue requirements of the government are sufficiently large. Although this can lead to some unusual results, they would take us too far afield, so we assume the non-negative consumption constraints are always slack.

${ }^{6}$ If income ranges were disjoint but contiguous, so $\bar{Y}^{1}=\underline{Y}^{2}$, a discontinuity would arise leading to the possibility of non-existence of the optimum. Because the income level $Y=\bar{Y}^{1}=\underline{Y}^{2}$ could be earned at both jobs 1 and 2 and each worker has different wage rates at different jobs, each worker's utility would change discontinuously with income around $Y=\bar{Y}^{1}=\underline{Y}^{2}$. In this case, the existence of an optimum would not be guaranteed. 
since the two incentive constraints cannot both be satisfied in this case. ${ }^{7}$ As well, case (iv) cannot arise because it will be possible to move $A_{2}$ to job 2 so as to keep worker 2 as well off while increasing government revenue without violating any incentive constraint. ${ }^{8}$ Cases (i) and (ii) are possible and we consider them in turn.

\subsection{Case (i): Both Workers in Most-Suited Jobs}

In this case, we can show that, in contrast to the standard intensive-margin case, when the optimal bundles $A_{1}$ and $A_{2}$ are in the interior of the income ranges of jobs 1 and 2 and the incentive constraint on the high-skilled worker is binding, the marginal tax rate on the low-skilled worker is negative, while that on the high-skilled worker is zero. In this case, the high-skilled worker is worse off than the low-skilled one. If the upper income bound becomes binding on worker 1 , his marginal tax rate can take any sign. If it becomes binding on worker 2, his marginal tax rate is positive. Moreover, unlike in the standard case, the incentive constraint on type- 2 workers need not be binding in the optimum, even though the government is averse to inequality. In this case, the optimum will be first-best. The following analysis demonstrates these results.

We continue to suppress job superscripts. We know that type-1 will never mimic type- 2 in the optimum since as we have seen, in the laissez-faire the type- 1 worker is worse off than the type-2, so a government with non-negative aversion to inequality will want to redistribute from the type- 2 to the type- 1 as in the standard model. The government then maximizes $\gamma_{1} V_{1}\left(C_{1}, Y_{1}\right)+\gamma_{2} V_{2}\left(C_{2}, Y_{2}\right)$ subject to its budget constraint, $\left(Y_{1}-C_{1}\right)+$ $\left(Y_{2}-C_{2}\right) \geq K$, the incentive constraint on the high-skilled, $V_{2}\left(C_{2}, Y_{2}\right) \geq \widehat{V}_{2}\left(C_{1}, Y_{1}\right)$, and

7 Proof: By the single-crossing property, indifference curves for workers 1 and 2 intersect at most once. Suppose worker 2's incentive constraint is satisfied, so $U\left(C_{2}^{1}, Y_{2}^{1} / w_{2}^{1}\right) \geq$ $U\left(C_{1}^{2}, Y_{1}^{2} / w_{2}^{2}\right)$. Also, $w_{1}^{1}>w_{2}^{1}$ implies $U\left(C_{2}^{1}, Y_{2}^{1} / w_{1}^{1}\right)>U\left(C_{2}^{1}, Y_{2}^{1} / w_{2}^{1}\right)$ and $w_{2}^{2}>w_{1}^{2}$ implies $U\left(C_{1}^{2}, Y_{1}^{2} / w_{1}^{2}\right)<U\left(C_{1}^{2}, Y_{1}^{2} / w_{2}^{2}\right)$. Therefore, $U\left(C_{2}^{1}, Y_{2}^{1} / w_{1}^{1}\right)>U\left(C_{1}^{2}, Y_{1}^{2} / w_{1}^{2}\right)$, so worker 1 's incentive constraint is violated. The same reasoning implies that if worker 1 's incentive constraint is satisfied, worker 2's will be violated.

8 The reason is that in this case, indifference curves will intersect in income range 1 when incentive constraints are satisfied. In range 2, the indifference curve for worker 1 will be everywhere above that for worker 2 , and the $45^{\circ}$ line tangent to the indifference curve of worker 2 in job 1 , say, $I_{2}^{1}$, is above the $45^{\circ}$ line tangent to that in job $2, I_{2}^{2}$. Therefore, a movement of $A_{2}$ from some point on $I_{2}^{1}$ to the unit-slope point of $I_{2}^{2}$ is a movement of less than $45^{\circ} \mathrm{s}$ and will increase government revenue without violating an incentive constraint. This is so even if the optimum is such that there is no unit-slope point on $I_{2}^{2}$. 
the income bounds, $\underline{Y}^{1} \leq Y_{1} \leq \bar{Y}^{1}$ and $\underline{Y}^{2} \leq Y_{2} \leq \bar{Y}^{2}$.

The Lagrange expression can be written:

$$
\begin{gathered}
\mathcal{L}=\gamma_{1} V_{1}\left(C_{1}, Y_{1}\right)+\gamma_{2} V_{2}\left(C_{2}, Y_{2}\right)+\lambda\left[\left(Y_{1}-C_{1}\right)+\left(Y_{2}-C_{2}\right)-K\right]+\mu\left[V_{2}\left(C_{2}, Y_{2}\right)-\widehat{V}_{2}\left(C_{1}, Y_{1}\right)\right] \\
+\underline{\delta}^{1}\left(Y_{1}-\underline{Y}^{1}\right)+\bar{\delta}^{1}\left(-Y_{1}+\bar{Y}^{1}\right)+\underline{\delta}^{2}\left(Y_{2}-\underline{Y}^{2}\right)+\bar{\delta}^{2}\left(-Y_{2}+\bar{Y}^{2}\right)
\end{gathered}
$$

The first-order conditions on $C_{1}$ and $Y_{1}$ for worker 1 , and $C_{2}$ and $Y_{2}$ for worker 2 are:

$$
\begin{array}{ll}
\gamma_{1} \frac{\partial V_{1}}{\partial C_{1}}-\lambda-\mu \frac{\partial \widehat{V}_{2}}{\partial C_{1}}=0 ; & \gamma_{1} \frac{\partial V_{1}}{\partial Y_{1}}+\lambda+\left(\underline{\delta}^{1}-\bar{\delta}^{1}\right)-\mu \frac{\partial \widehat{V}_{2}}{\partial Y_{1}}=0 \\
\gamma_{2} \frac{\partial V_{2}}{\partial C_{2}}-\lambda+\mu \frac{\partial V_{2}}{\partial C_{2}}=0 ; & \gamma_{2} \frac{\partial V_{2}}{\partial Y_{2}}+\lambda+\left(\underline{\delta}^{2}-\bar{\delta}^{2}\right)+\mu \frac{\partial V_{2}}{\partial Y_{2}}=0
\end{array}
$$

The interpretation of these results will differ depending on whether the income constraints are binding. Consider first the case where they are not, which corresponds with the standard case.

\section{Income Constraints not Binding}

In this case, $\underline{\delta}^{j}=\bar{\delta}^{j}=0$ for $j=1,2$, so (1) and (2) reduce to the first-order conditions of the standard case (Stiglitz 1982). However, there are three important differences here compared with the standard case.

First, it is possible that the incentive constraint is slack in the optimum, and related to this, the first-best maximin outcome can be achieved in the second-best. In the standard case, the incentive constraint on high-skilled workers must bind in an optimum when the social welfare function has non-negative aversion to inequality. The reason is that when the incentive constraint is satisfied, type-2's must be better off than type- 1 's. ${ }^{9}$ In our model, the mimicking type-2 need not be better off than the type- 1 worker for the incentive constraint to be satisfied. That is because the mimicker earns a lower wage rate in job 1 than does the type-1 worker by Assumption 1(ii) (i.e., $w_{1}^{1}>w_{2}^{1}$ ). Therefore, it is possible that the incentive constraint is not binding in the optimum, depending on the relative wage rates $w_{1}^{1}$ and $w_{2}^{1}$ and the relative values of social welfare weights $\gamma_{1}$ and $\gamma_{2}$.

9 That is, $V_{2}\left(C_{2}, Y_{2}\right) \geq \widehat{V}_{2}\left(C_{1}, Y_{1}\right)>V_{1}\left(C_{1}, Y_{1}\right)$ since the mimicker supplies less labour to earn the same income as a type-1 person. 
This outcome can be pictured by starting from the laissez-faire outcome given by points $\ell_{1}$ and $\ell_{2}$ in Figure 2, and redistributing income lump-sum from the type-2 to the type- 1 worker. The $45^{\circ}$ budget line of the type- 2 falls and that of the type- 1 rises, and both segments of their indifference curves shift as well. The optimum might be achieved without the incentive constraint becoming binding as illustrated in Figure 3, where now $I_{i}^{j}$ denotes the indifference curve of a type- $i$ worker in job $j$. In this case, the Lagrange multiplier on the incentive constraint $\mu$ is zero, implying by (1) and (2) that $\left(\partial V_{1} / \partial Y_{1}\right) /\left(\partial V_{1} / \partial C_{1}\right)=$ $\left(\partial V_{2} / \partial Y_{2}\right) /\left(\partial V_{2} / \partial C_{2}\right)=1$. Thus, marginal tax rates are zero and a first-best social outcome is achieved.

Note in particular that a maximin outcome can be achieved as long as revenue requirement is not too extreme, making the maximin technologically infeasible. This is because, when the two types have the same level of utility, $I_{2}^{1}$ is above $I_{1}^{1}$ and $I_{1}^{2}$ is above $I_{2}^{2}$ due to Assumption 1(ii). In fact, since these indifference curves are some distance apart, first-best outcomes "near" the equal-utility maximin outcome can also be achieved in the second best.

Second, when the incentive constraint is binding, so $\mu>0$, the optimal marginal tax rate on the type- 1 worker will be negative. Figure 4 illustrates this case. For the highskilled worker, (2) implies that $\left(\partial V_{2} / \partial Y_{2}\right) /\left(\partial V_{2} / \partial C_{2}\right)=1$ when income constraints are not binding, so the marginal tax rate at the top is zero as in the standard case. For the low-skilled worker, (1) can be written:

$$
-\frac{\partial V_{1} / \partial Y_{1}}{\partial V_{1} / \partial C_{1}}=\frac{\lambda-\mu\left(\partial \widehat{V}_{2} / \partial Y_{1}\right)}{\lambda+\mu\left(\partial \widehat{V}_{2} / \partial C_{1}\right)}=\frac{1-k\left(\partial \widehat{V}_{2} / \partial Y_{1}\right) /\left(\partial \widehat{V}_{2} / \partial C_{1}\right)}{1+k}
$$

where $k=\left(\mu \partial \widehat{V}_{2} / \partial C_{1}\right) / \lambda>0$. As Figure 4 shows, $-\left(\partial \widehat{V}_{2} / \partial Y_{1}\right) /\left(\partial \widehat{V}_{2} / \partial C_{1}\right)>1$, implying that $-\left(\partial V_{1} / \partial Y_{1}\right) /\left(\partial V_{1} / \partial C_{1}\right)>1$. Therefore, the marginal tax rate for the type-1 worker is negative, contrary to the standard case. ${ }^{10}$

Third, whether or not the incentive constraint is binding, the type-1 worker can be better off than the type- 2 worker in an optimum. If the incentive constraint binds, type- 2

10 More formally, rewrite (3) as $x=(1+k y) /(1+k)$, or $x-1=k(y-x)$, where $x$ and $y$ are the marginal rates of substitution at $\left(C_{1}, Y_{1}\right)$ of workers 1 and 2 . By the single-crossing property in the feasible income range for job $1, y>x$. Therefore, $x>1$, which implies a negative marginal tax rate. 
worker earns a lower wage than type-1 when he is mimicking the latter's income. Therefore, $V_{1}\left(C_{1}, Y_{1}\right)>\widehat{V}_{2}\left(C_{1}, Y_{1}\right)=V_{2}\left(C_{2}, Y_{2}\right)$.

The intuition for the negative marginal tax rate for worker 1 is clear. When each worker works at his most productive job, worker 2 has a higher wage rate than worker 1 . However, by Assumption 1(ii) worker 2 has a lower wage rate when he mimics worker 1 by working in job 1 . Since the incentive constraint prevents a less-productive worker from mimicking a more-productive worker, it is optimal for the tax system to encourage, rather than discourage, worker 1's labour supply, as long as his income remains in the income range for job 1. Clearly, it is important that worker 1 is more productive in job 1 than is the more highly skilled worker 2 . If that were not the case, the standard result of a positive marginal tax rate at the bottom would apply.

\section{Income Constraints Binding}

The fact that incomes are bounded for each type of job leads to the possibility that in an optimum, income constraints will be binding. To explore the possibilities, assume that in the laissez-faire both worker-types are in the interior of the income range for their mostsuited job as in Figure 2. Redistribution from type-2's to type-1's will initially cause the allocation for the type-2's to move in a southeast direction, and for the type 1's to move northwest. That implies that if the income constraint binds for type-2's, it will be at $\bar{Y}^{2}$, while for type-1's it will be at $\underline{Y}^{1}$, at least as long as the government is purely redistributive. If the government requires positive revenue, it is possible that $Y_{1} \leq \bar{Y}^{1}$ becomes binding if revenue requirements are large enough. The following cases are then possible.

i) $Y_{2} \leq \bar{Y}^{2}$ is binding: If the income of the type-2 worker is strictly constrained by the type-2 job upper bound, $\bar{\delta}^{2}>0,{ }^{11}$ while $\underline{\delta}^{2}=0$. First-order conditions (2) then yield:

$$
-\frac{\partial V_{2} / \partial Y_{2}}{\partial V_{2} / \partial C_{2}}=\frac{\lambda-\bar{\delta}^{2}}{\lambda}<1
$$

Therefore, the marginal tax rate at the top will be positive. This reflects the fact that type-2's indifference curve will have a slope less than unity everywhere in the income range $\left[\underline{Y}^{2}, \bar{Y}^{2}\right]$.

11 Technically, it is possible for $\bar{\delta}^{2}=0$ and $Y_{2}=\bar{Y}^{2}$ simultaneously. For simplicity, we ignore all such boundary cases in what follows. 
ii) $Y_{1} \geq \underline{Y}^{1}$ is binding: Similar reasoning applies if the type-1 worker is strictly incomeconstrained at $\underline{Y}^{1}$. Then, the multipliers satisfy $\underline{\delta}^{1}>0$ and $\bar{\delta}^{1}=0$, and first-order conditions (1) reduce to:

$$
-\frac{\partial V_{1} / \partial Y_{1}}{\partial V_{1} / \partial C_{1}}=\frac{\lambda+\underline{\delta}^{1}-\mu\left(\partial \widehat{V}_{2} / \partial Y_{1}\right)}{\lambda+\mu\left(\partial \widehat{V}_{2} / \partial C_{1}\right)}=\frac{1+\underline{\delta}^{1} / \lambda-k\left(\partial \widehat{V}_{2} / \partial Y_{1}\right) /\left(\partial \widehat{V}_{2} / \partial C_{1}\right)}{1+k}
$$

The additional term in the numerator makes the marginal tax rate on the type-1's even more negative.

iii) $Y_{1} \leq \bar{Y}^{1}$ is binding: With positive revenue requirements, both workers may pay positive taxes and the maximum income constraint on type-1 may bind (and that on type-2 may as well). In this case, first-order condition (1) becomes:

$$
-\frac{\partial V_{1} / \partial Y_{1}}{\partial V_{1} / \partial C_{1}}=\frac{\lambda-\bar{\delta}^{1}-\mu\left(\partial \widehat{V}_{2} / \partial Y_{1}\right)}{\lambda+\mu\left(\partial \widehat{V}_{2} / \partial C_{1}\right)}=\frac{1-\bar{\delta}^{1} / \lambda-k\left(\partial \widehat{V}_{2} / \partial Y_{1}\right) /\left(\partial \widehat{V}_{2} / \partial C_{1}\right)}{1+k}
$$

The presence of $-\bar{\delta}^{1} / \lambda$ in the numerator implies that worker 1's marginal tax rate may take either sign.

Note that, as in the case without binding income constraints, the incentive constraint may still be slack. First-best maximin utility levels and those near the maximin can still be achieved in the second-best, even when some worker is income constrained. The only difference is that the marginal tax rates of the income-constrained worker is no longer zero, as shown for the three possible cases above.

Also note that, when preferences are quasilinear-in-consumption, the type-1 worker's marginal tax rate will always be negative as long as the incentive constraint is binding, whether or not $\bar{Y}^{1}$ binds. Because we assumed that each worker works at his most productive job and is not income-constrained in the laissez-faire, the slope at $\bar{Y}^{1}$ of the type-1 worker's indifference curve through his laissez-faire allocation is greater than unity. With quasilinear-in-consumption preferences, this will also be true for any of his indifference curves, including the one through his optimal allocation.

\subsection{Case (ii): Both Workers in Job 2}

This case is similar to the standard model if no income constraints are binding, and the standard government problem applies. The type- 2 worker is more productive than type- 1 
in job 2, and redistribution also goes from type-2 to type-1. Figure 5 depicts an optimum at bundles $A_{1}$ and $A_{2}$ in this case. Standard results apply, with zero marginal tax rates at the top and positive ones at the bottom.

The existence of separate jobs with income bounds, however, leads to two modifications of the standard model. First, if $A_{1}$ is in the interior of income range 2 but is close enough to the lower income bound $\underline{Y}^{2}$, moving it into income range 1 may increase revenue without violating any constraint, so the proposed Case (ii) optimum is not globally optimal. Figure 5 illustrates this possibility. If $A_{1}$ were on the dotted segment, it may be dominated by some allocations on the same indifference curve near or at the upper bound of income range 1 . This occurs when the movement from $A_{1}$ to such allocations is at more than 45 degrees and therefore can increase government revenue without violating any constraint.

Second, if one or both of the optimal bundles $A_{1}$ and $A_{2}$ hits the upper income bound $\bar{Y}^{2}$, both types' marginal tax rate will be positive. To see this, note first that $A_{2}$ cannot hit the lower income bound. Our assumptions that each worker works at his most productive job and is not income-constrained in the laissez faire, together with a non-negative revenue requirement, imply that the slopes of type- 2 worker's indifference curves at the lower income bound $\underline{Y}^{2}$ are always less than unity in an optimum. So moving $A_{2}$ up the indifference curve increases revenue without violating any constraint. It is, however, possible for $A_{2}$ to be located at the upper income bound $\bar{Y}^{2}$. In that case, type-2's indifference curve has a slope less than unity at that bound.

By the same token, $A_{1}$ may also be located at the upper income bound, where the slope of type-1's indifference curve is less than unity. When this is the case, pooling will occur if type-2's incentive constraint binds in an optimum. ${ }^{12} A_{1}$ may also be at the lower bound, where type-1's indifference curve has a slope less than unity. Thus, no matter where $A_{1}$ is in income range 2 , type-1's marginal tax rate is positive. When $A_{2}$ is at the upper bound, type-2's marginal tax rate is positive.

12 For the standard reason, pooling cannot occur in the interior of income range 2. 


\subsection{Tax Implementation}

Let us now briefly discuss the implementation of optimal allocations with a tax function $T(Y)$, or equivalently, a consumption function $C(Y)$. Since Case (ii) is similar to a standard model, we only discuss Case (i), focusing on the interior case where the incentive constraint binds, depicted in Figure 4. For convenience, we assume that indifference curves never touch the horizontal axis.

Following the literature (e.g., Homburg 2002), one can focus on the lower envelope of the indifference curves through optimal allocations when finding the relevant consumption function $C(Y)$. Then, to implement the optimum allocation $\left(A_{1}, A_{2}\right)$ in Figure 4, the $C(Y)$ will coincide with $I_{2}^{1}$ up to $A_{1}$, kink at that point, coincide with or run below $I_{1}^{1}$ to reach the lower endpoint of $I_{2}^{2}$, rise along $I_{2}^{2}$ up to $A_{2}$, and then go below or coincide with $I_{2}^{2}$ afterwards. Note that the kink at $A_{1}$ remains as long as $A_{1}$ does not hit the upper income bound $\bar{Y}^{1}$. This pattern is obviously more complicated than in the standard case. In particular, we can make the following two observations about $C(Y)$.

First, unlike in the standard case, as the type-distribution becomes dense and eventually continuous, a continuous consumption function may still not become smooth. As can be seen from Figure 4, consumption at the upper end of $I_{2}^{1}$ may be higher or lower than that at the lower end of $I_{2}^{2}$. If $A_{1}$ is near or at $\underline{Y}^{1}$, a continuous consumption function implementing the optimal allocations needs to have a decreasing segment between $Y=\bar{Y}^{1}$ and $Y=\underline{Y}^{2}$, in order to extend from $A_{1}$ to the lower end of $I_{2}^{2}$. Thus, optimal consumption levels may not monotonically increase with income, depending on the shape of indifference curves, differences in job-specific wage rates of a given worker, the sizes of gaps between income ranges, the government revenue requirement, and the welfare weights.

Second, in a standard model, optimal tax structures exist for which the left derivative of the tax function is equal to one minus the marginal rate of substitution (Homburg 2002), which is the definition of the marginal tax rate we used. However, in our model, this may not be the case. In Figure 4, for example, it is the right derivative of such tax functions that is equal to the marginal tax rate for worker 1 , which as we have seen is negative. 


\subsection{Utility Possibilities Frontier (UPF)}

The second-best UPF for Case (i) has an interesting feature: a utilitarian optimum is more redistributive than a maximin optimum in terms of utility levels. That is, starting from the laissez-faire, there is more redistribution from the type- 2 worker to the type- 1 worker under utilitarianism than under maximin. Figure 6 illustrates. The first- and second-best UPF's are the lighter curves labeled $A M_{f} N U_{f}$ and $A M_{s} N U_{s} N^{\prime}$, respectively.

The reason for this result is the following. First, for the same reason as in the standard model, a first-best utilitarian optimum involves worker 1 having higher utility than worker 2. Second, as shown in section 3.1.1, incentive constraints are still slack in or "near" a maximin optimum. Thus, starting from a maximin, further redistribution toward worker 1 along the first-best UPF is still possible. Therefore, a second-best utilitarian optimum will be more redistributive than a maximin optimum in terms of the relative level of utility.

This contrasts with the second-best outcome in a standard model, where a utilitarian optimum is always less redistributive than a maximin one because worker 2 can never be made worse off than worker 1.

\subsection{Comparing Case (i) and Case (ii) Optima}

It is instructive to characterize the circumstances in which each case is globally optimal. This involves a comparison between discretely different allocations, which is difficult to do analytically. However, graphical and numerical approaches suffice to suggest the following finding. When the income range of job 1 is not too small relative to that of job 2, Case (i) typically dominates Case (ii), for various levels of revenue requirement and degrees of intended redistribution. ${ }^{13}$ However, when income range 1 is small compared to income range 2, Case (i) is no longer always superior. It is more likely to be overall optimal, the lower is the revenue requirement and the more redistributive is the government objective. Conversely, Case (ii) is more likely to be optimal when the revenue requirement is very

13 A higher degree of intended redistribution here means a higher $\gamma_{1} / \gamma_{2}$ ratio, that is, steeper social indifference curves of the weighted utilitarian social welfare function. In our model, in both the first-best and the second-best solutions for Case (i), utilitarianism turns out to be more redistributive in terms of relative utility levels than maximin. So "more redistributive" does not correspond to higher aversion-to-inequality or more concavity in a social welfare function. 
high and redistribution is less important.

Begin with the graphical approach and refer to the laissez-faire in Figure 2 (points $\ell_{1}$ and $\ell_{2}$ ), and to Cases (i) and (ii) in Figures 4 and 5, respectively. First, we can show that a purely redistributive optimum necessarily belongs to Case (i) rather than Case (ii).

To see this, recall the single-crossing property of the two workers' indifference curves. In the laissez-faire, $I_{1}$ and $I_{2}$ either intersect in income range 2 or do not intersect at all, and in the latter case, $I_{1}^{2}$ lies above $I_{2}^{2}$. Also note that, in a purely redistributive optimum, $A_{1}$ must be on an $I_{1}$ that is higher than the laissez-faire allocation $\ell_{1}$. Next, for those $I_{1}$ 's lying above the laissez-faire $I_{1}$, a movement from any point on $I_{1}^{2}$ to the upper endpoint of $I_{1}^{1}$ — that is, the point where indifference curve $I_{1}^{1}$ hits the income bound $\bar{Y}^{1}$ — is more than 45 degrees. ${ }^{14}$ Finally, by the single-crossing property, $I_{1}^{1}$ lies below $I_{2}^{1}$ in any Case (ii) optimum when the incentive constraint is binding and $I_{1}^{2}$ and $I_{2}^{2}$ are intersecting.

With these observations, we deduce that starting from a Case (ii) purely redistributive optimum, moving $A_{1}$ to income range 1 will increase revenue without violating any constraint and will thus allow for further redistribution. Moreover, starting from a Case (i) optimum, one cannot find a movement of $A_{1}$ into income range 2 that allows for further redistribution. By the single-crossing property, $I_{1}^{2}$ lies above $I_{2}^{2}$ in a Case (i) optimum when the incentive constraint is binding. So moving $A_{1}$ up $I_{1}$ into income range 2 will violate both worker 2's incentive constraint and the government budget constraint. Thus, an overall optimum must belong to Case (i) when the revenue requirement is zero so the government problem is a purely redistributive one. This is the case no matter how redistributive the government's preferences are. Therefore, a Case (i) optimum will tend to be overall optimal when the revenue requirement is not too high.

On the other hand, the effects of other configurations of parameter values are difficult to derive analytically, so we resort to simulations. The following simulations are represen-

14 To see this, imagine a figure similar to Figure 5 but drawn for the purely redistributive case. First, note that $w_{1}^{1}>w_{1}^{2}$ according to Assumption 1 (i). So if we extend $I_{1}^{2}$ into income range 1 , it will be above the upper endpoint of $I_{1}^{1}$. By our assumptions that both workers works in their most suited jobs and are not income-constrained in the laissez-faire, for those $I_{1}$ 's lying above the laissez-faire one, the slope at the upper end point of $I_{1}^{1}$ and the slope at the lower end point of $I_{1}^{2}$ are both greater than unity, and the latter is greater than the former. Therefore, the above movement is more than 45 degrees. 
tative. The utility function takes the Cobb-Douglas form, $U(C, L)=C^{0.64}(\bar{H}-L)^{0.36}$, where $C$ is consumption, $\bar{H}=1.00001$ is time endowment, and $L$ is labour supply. Jobspecific wage rates are $w_{1}^{1}=0.6, w_{1}^{2}=0.45, w_{2}^{1}=0.5$, and $w_{2}^{2}=1$. The income bounds are $\underline{Y}^{1}=0.1, \bar{Y}^{1}=0.3999, \underline{Y}^{2}=0.4$, and $\bar{Y}^{2}=1$, and for comparison, we also used other values. Revenue requirement increases from the purely redistributive level of zero to 1.15. We used grid search to compute the utility possibilities frontiers for both cases in both the first- and the second-best.

Figure 6 shows an example. Under this model specification, the highest technologically possible revenue is around 1.3, so a revenue requirement of 0.5 is in the lower middle range. As can be seen in the figure, Case (i) second-best UPF, $A M_{s} N U_{s} N^{\prime}$, dominates Case (ii) second-best UPF, $a m_{s} n^{\prime}$, except at the upper left segment. A pure utilitarian social welfare function corresponds to $\gamma_{1} / \gamma_{2}=1$ and has contour lines with slopes of minus one. So a Case (i) utilitarian outcome will be at $U_{s}$, while a Case (ii) one will be at $u_{s}$. Clearly, social welfare is higher in Case (i). A similar argument applies in the maximin case. In fact, for all values of $\gamma_{1} / \gamma_{2}$ in the range from (minus) the slope of line $a A$ in Figure 6 to close to infinity, social welfare under a weighted utilitarian social welfare function will be higher in Case (i) than in Case (ii).

As revenue requirement increases, the UPF's shrink towards the origin. However, the Case (i) UPF's may or may not shrink more quickly than the Case (ii) ones, depending on the relative size of income ranges 1 and 2. We considered three sets of income ranges. In all three, $\underline{Y}^{1}=0.1$ and $\bar{Y}^{2}=1$. However, the division points are $\left(\bar{Y}^{1}=0.1999, \underline{Y}^{2}=0.2\right)$, $\left(\bar{Y}^{1}=0.2999, \underline{Y}^{2}=0.3\right)$, and $\left(\bar{Y}^{1}=0.3999, \underline{Y}^{2}=0.4\right)$, respectively. In the latter two, Case (i) UPF's largely maintain the same relative position to Case (ii) UPF's as that in Figure 6. So, Case (i) typically dominates Case (ii). However, in the first case, where income range 1 is relatively small as compared to income range 2, Case (i) UPF's shrink faster than Case (ii) ones and eventually become dominated. Then, Case (ii) will be the global optimum. 


\subsection{Summary of Results in the Two-Type Case}

The following summarizes the main results obtained in the two-type case.

i) In both the first-best and the second-best, the utilitarian optimum is more redistributive than the maximin optimum.

ii) It is possible that first-best levels of utilities be achieved with a non-linear income tax schedule in the second-best, in which case the incentive constraint is not binding.

iii) If the incentive constraint binds in the second-best, an optimum may be one with each worker working in his most suited job (Case i) or one with both workers in the high income job (Case ii). A lower revenue requirement and a higher redistributive preference tend to favour Case (i), and vice versa.

iv) In the Case (i) optimum, the low-skilled worker's marginal tax rate is negative if his upper income bound is not binding; otherwise, it may take either sign. The highskilled worker's marginal tax rate is zero if his upper income bound does not bind; otherwise, it is positive. Moreover, the low-skilled worker's optimum consumption may be higher than the high-skilled worker's, implying that consumption may not increase with income.

v) The Case (ii) optimum is qualitatively the same as that of a standard model, with the exception that if the upper income bound binds for the high-skilled worker, his marginal tax rate will be positive.

\section{Extension to Multiple Types}

In this section, we extend the basic model to allow for multiple types of workers and jobs. Suppose there are $N$ worker-types and $N$ job-types. To facilitate discussion, we again consider only disjoint income ranges and focus on optima where each worker works at his most productive job. ${ }^{15}$ All other assumptions are retained. We show that the main result of the basic model generalizes: A worker's marginal tax rate will be negative under

15 Needless to say, the latter assumes away the possibility of occupational distortions by the tax system and removes potentially interesting optima from our consideration. However, when $N$ is not small, there can be many ways in which workers' occupational choices are distorted away from their most productive ones, and as we have seen, making discrete comparisons when occupations can be distorted is difficult. Exploring properties of an optimum when this restriction is dropped is left for future research. 
conditions similar to those in the basic model. As well, marginal tax rates can be zero below the top.

As in the previous section, suppose for simplicity that there is one representative worker of each type. The government objective is the weighted utilitarian social welfare function, $\sum_{i=1}^{N} \gamma_{i} V_{i}\left(C_{i}, Y_{i}\right)$, where $\gamma_{1}, \cdots, \gamma_{N}$ are positive weights. The government maximizes social welfare subject to the budget constraint $\sum_{i=1}^{N}\left(Y_{i}-C_{i}\right) \geq K$, the incentive constraints, $V_{i}\left(C_{i}, Y_{i}\right) \geq \widehat{V}_{i}\left(C_{i^{\prime}}, Y_{i^{\prime}}\right), \forall i, i^{\prime} \neq i$, and the income bounds, $\underline{Y}^{i} \leq Y_{i} \leq \bar{Y}^{i}, \forall i$.

The Lagrange expression for the government problem can be written:

$$
\begin{aligned}
\mathcal{L}=\sum_{i=1}^{N} \gamma_{i} V_{i}\left(C_{i}, Y_{i}\right)+\lambda & {\left[\sum_{i=1}^{N}\left(Y_{i}-C_{i}\right)-K\right]+\sum_{i=1}^{N} \sum_{i^{\prime} \neq i} \mu_{i \rightarrow i^{\prime}}\left[V_{i}\left(C_{i}, Y_{i}\right)-\widehat{V}_{i}\left(C_{i^{\prime}}, Y_{i^{\prime}}\right)\right] } \\
& +\sum_{i=1}^{N} \underline{\delta}^{i}\left(Y_{i}-\underline{Y}^{i}\right)+\sum_{i=1}^{N} \bar{\delta}^{i}\left(-Y_{i}+\bar{Y}^{i}\right)
\end{aligned}
$$

where $\mu_{i \rightarrow i^{\prime}}$ is the multiplier for the incentive constraint that prevents worker $i$ from mimicking worker $i^{\prime}$. Note that both upward and downward incentive constraints are included, because no restriction has been imposed on the social welfare weights. Also, global as well as local ones are included. We shall write $\mu_{i \rightarrow i^{\prime}}^{d}$ when the relevant incentive constraint is a downward one and $\mu_{i \rightarrow i^{\prime}}^{u}$ when it is an upward one. To simplify notation, we denote $V_{i}\left(C_{i}, Y_{i}\right)$ by $V_{i}$ and $\widehat{V}_{k}\left(C_{i}, Y_{i}\right)$ by $\widehat{V}_{k}$ in what follows.

The first-order conditions on $C_{i}$ and $Y_{i}$ are

$$
\begin{gathered}
\left(\gamma_{i}+\sum_{k>i} \mu_{i \rightarrow k}^{u}+\sum_{k<i} \mu_{i \rightarrow k}^{d}\right) \frac{\partial V_{i}}{\partial C_{i}}-\lambda-\sum_{k<i} \mu_{k \rightarrow i}^{u} \frac{\partial \widehat{V}_{k}}{\partial C_{i}}-\sum_{k>i} \mu_{k \rightarrow i}^{d} \frac{\partial \widehat{V}_{k}}{\partial C_{i}}=0 \\
\left(\gamma_{i}+\sum_{k>i} \mu_{i \rightarrow k}^{u}+\sum_{k<i} \mu_{i \rightarrow k}^{d}\right) \frac{\partial V_{i}}{\partial Y_{i}}+\lambda+\underline{\delta}^{i}-\bar{\delta}^{i}-\sum_{k<i} \mu_{k \rightarrow i}^{u} \frac{\partial \widehat{V}_{k}}{\partial Y_{i}}-\sum_{k>i} \mu_{k \rightarrow i}^{d} \frac{\partial \widehat{V}_{k}}{\partial Y_{i}}=0
\end{gathered}
$$

These can be rearranged to give

$$
\begin{aligned}
-\frac{\partial V_{i} / \partial Y_{i}}{\partial V_{i} / \partial C_{i}}=1 & +\frac{1}{\lambda}\left(\underline{\delta}^{i}-\bar{\delta}^{i}\right)+\frac{1}{\lambda} \sum_{k<i} \mu_{k \rightarrow i}^{u} \frac{\partial \widehat{V}_{k}}{\partial C_{i}}\left[-\frac{\partial \widehat{V}_{k} / \partial Y_{i}}{\partial \widehat{V}_{k} / \partial C_{i}}+\frac{\partial V_{i} / \partial Y_{i}}{\partial V_{i} / \partial C_{i}}\right] \\
& +\frac{1}{\lambda} \sum_{k>i} \mu_{k \rightarrow i}^{d} \frac{\partial \widehat{V}_{k}}{\partial C_{i}}\left[-\frac{\partial \widehat{V}_{k} / \partial Y_{i}}{\partial \widehat{V}_{k} / \partial C_{i}}+\frac{\partial V_{i} / \partial Y_{i}}{\partial V_{i} / \partial C_{i}}\right]
\end{aligned}
$$


Except for $-\bar{\delta}^{i}$, all other terms on the right-hand side are non-negative; in particular, the two differences in marginal rates of substitution in square brackets are positive because of Assumption 1(ii) that worker $i$ is more productive at job $i$ than other workers $k \neq i$.

We can infer from (9) that the slope of worker $i$ 's indifference curve at his optimal allocation will be strictly greater than unity and his marginal tax rate will be negative, if the following two conditions are satisfied:

(1) the constraint on income $Y_{i} \leq \bar{Y}^{i}$ is slack so that $\bar{\delta}^{i}=0$, or does not bind too much so that $\bar{\delta}^{i}$ is sufficiently small, and

(2) at least one incentive constraint preventing some other type $k$ from mimicking type $i$ is binding (or, roughly equivalently, there is some redistribution towards type $i$ ).

When condition (2) holds but condition (1) does not, $\bar{\delta}^{i}>0$ may be large enough to make type $i$ 's marginal tax rate positive. As noted in the basic model, this is likely to occur when revenue requirement is high and the tax system is set to encourage more work by worker $i$. An exception is when preferences are quasilinear-in-consumption, in which case the marginal tax rate will always be negative.

In any case, a negative marginal tax rate comes from Assumption 1(ii) that a worker is more productive than others at the job that suits him best. With this assumption, redistribution towards any type of worker calls for an upward distortion of his labour supply in order to provide an incentive to, and extract revenue from, the types from which the tax system redistributes.

In this model with multiple types, global as well as local incentive constraints may bind in an optimum. The derivation above does not allow one to determine which incentive constraints will bind. In Boadway, Song, and Tremblay (2013), we explored this issue using the 'utility curve' tool of Matthews and Moore (1987) and analyzed a simple 3-by-3 example. One result of that analysis is that the marginal tax rate below the top may be zero, due to a binding global incentive constraint.

\section{Other Extensions and Concluding Remarks}

This paper characterized optimal income taxation in a setting where workers of different skills are better suited for different jobs. It was shown that, relative to more standard 
settings, optimal taxation may involve more redistribution if jobs differ in the range of available income they offer and if individuals are more productive than others at the jobs that suit them best. For those to whom the tax system redistributes, negative marginal tax rates can often arise, because mimickers are locally less productive than these workers. For those from whom the tax system redistributes, even those who are not the most skilled may also face zero marginal tax rates. Moreover, first-best maximin outcomes may be attained using second-best nonlinear income tax policies. Analogous results on marginal tax rates obtain when there are multiple types.

A key assumption of the paper, Assumption 1(ii) on absolute advantage in workers' job-specific productivity, may not always hold. Some workers may be more/less productive than others at all jobs and therefore do not have an absolute advantage. In fact, the pattern of individuals' comparative advantage and absolute advantage can be complex. Some may do very well at any job. Others may be experts in certain jobs only. Still others may be able to do many jobs but are not the most productive at any job. This does not necessarily affect our main results. For example, it does not necessarily mean that negative marginal tax rates cannot arise below the top. Consider the case where there is a worker who is more productive than others at any job. As long as some worker below the top is more productive than his potential mimickers and the top worker is not among those potential mimickers, the former still faces a negative marginal tax (as long as his upper income bound does not bind too much). In this sense, Assumption 1(ii) can be relaxed to some extent.

In reality, different workers may also have different disutilities-of-work in different jobs. In Boadway, Song, and Tremblay (2013), we explored the consequence of introducing this feature into our model. As in Diamond (2006) and, more closely, Boadway et al (2002), suppose that the utility function is $U(C, L)=u(C)-\alpha_{i}^{j} L=u(C)-\alpha_{i}^{j} Y / w_{i}^{j}$, where $\alpha_{i}^{j}$ is worker $i$ 's job-specific disutility parameter at job $j$. Thus, workers differ in both productivities and preferences. Optimal income taxation in such a model has been analyzed by Boadway et al (2002), and their focus was on the consequences of giving various welfare weights to individuals with different preferences.

For our purpose, having job-specific disutility beside job-specific productivity makes 
our model more flexible. By varying parameter values, the standard model and our basic model above can emerge as special cases. Following Boadway et al (2002), define $\widehat{w}_{i}^{j} \equiv$ $w_{i}^{j} / \alpha_{i}^{j}$. Then we have $V_{i}^{j}(C, Y)=u(C)-Y / \widehat{w}_{i}^{j}$. If $\widehat{w}_{i}^{j}$ satisfy Assumption 1 , the model will be equivalent to the basic model in terms of results. Note that only $\widehat{w}_{i}^{j}$ are required to satisfy Assumption 1, so each worker's wage rates can actually be constant across jobs $\left(w_{i}^{1}=w_{i}^{2}, i=1,2\right)$, just as in a standard model. Therefore, introducing job-specific disutilities gives us an extra degree of freedom that enables us to completely do away with the assumptions on job-specific productivities. On the other hand, if Assumptions 1(i) (comparative advantage) and 1(iii) (ordering of highest wage rates) hold for $\widehat{w}_{i}^{j}$ but not 1(ii) (absolute advantage), the model resembles a standard model.

In Boadway, Song, and Tremblay (2013), we also extended the multiple-type model to include a labour market participation decision, as in Diamond (1980) and, more closely, Jacquet et al (2013). Two results emerge. First, the participation margin tends to increase the absolute value of the marginal tax rates for working individuals, whether they are positive or negative. Second, under some assumptions on welfare weights, the influence of the extensive margin and the combined influence of the intensive margin and the job-choice margin tend to have opposite effects on the levels of the participation taxes. For lower-skill workers, extensive-margin effects call for lower (and possibly negative) participation taxes while intensive-margin effects call for higher (and possibly positive) ones, and vice versa for higher-skill workers. This finding is similar to that of Jacquet et al (2013).

These and other possible extensions may be further pursued in future research. 


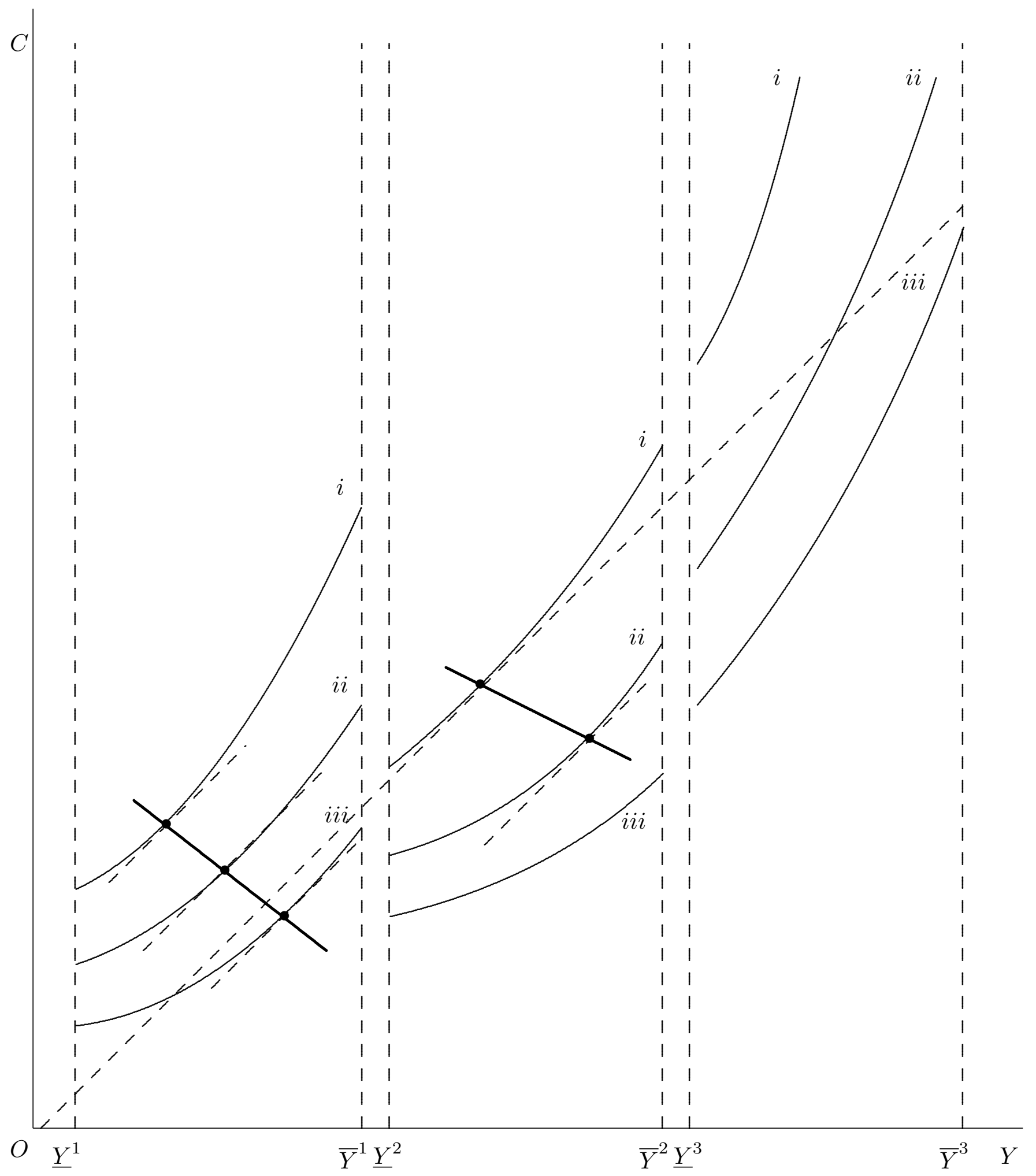

Figure 1

Three Indifference Curves of Worker 2 


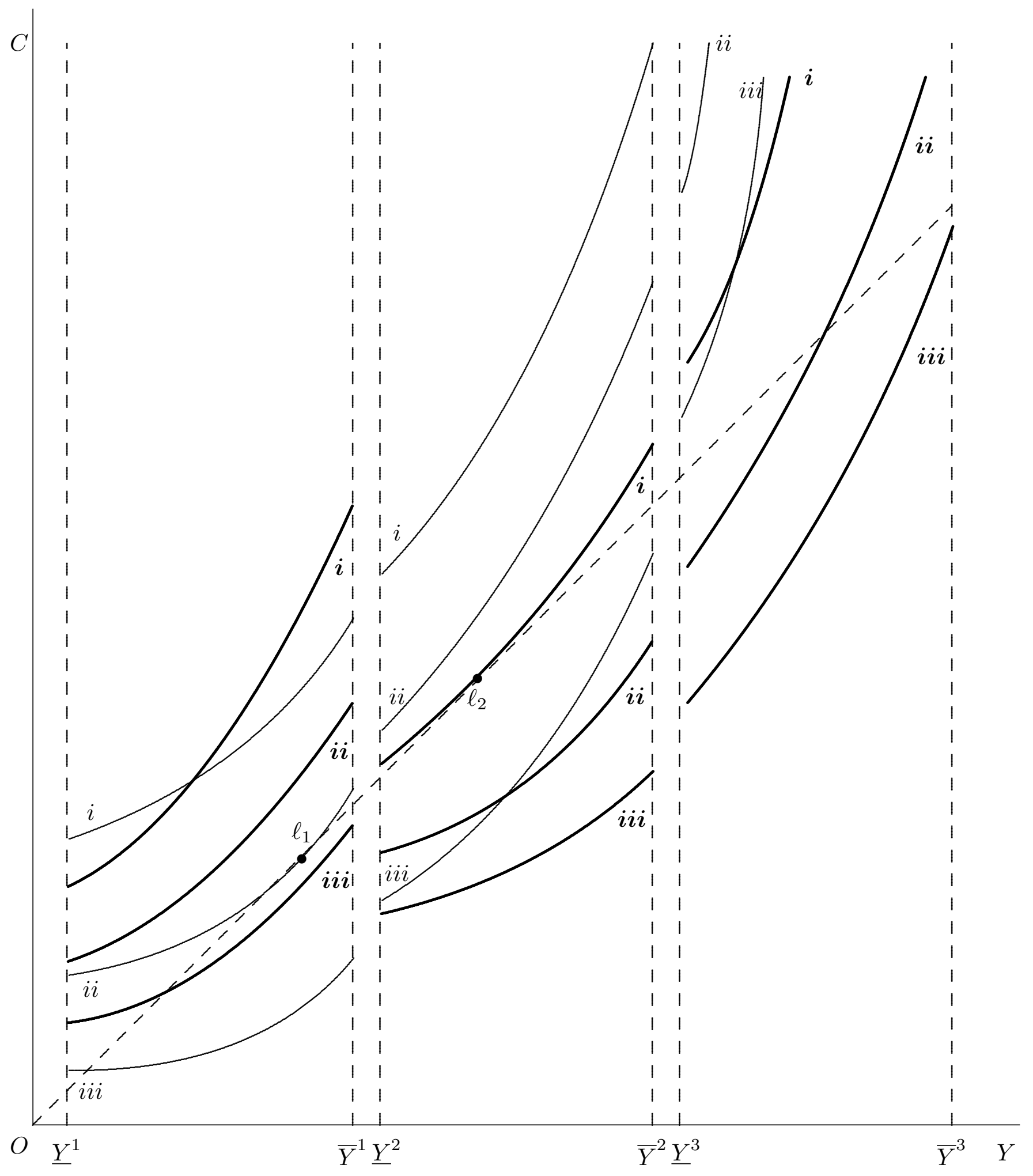

Figure 2

Indifference Curves of Worker 1 and Worker 2 


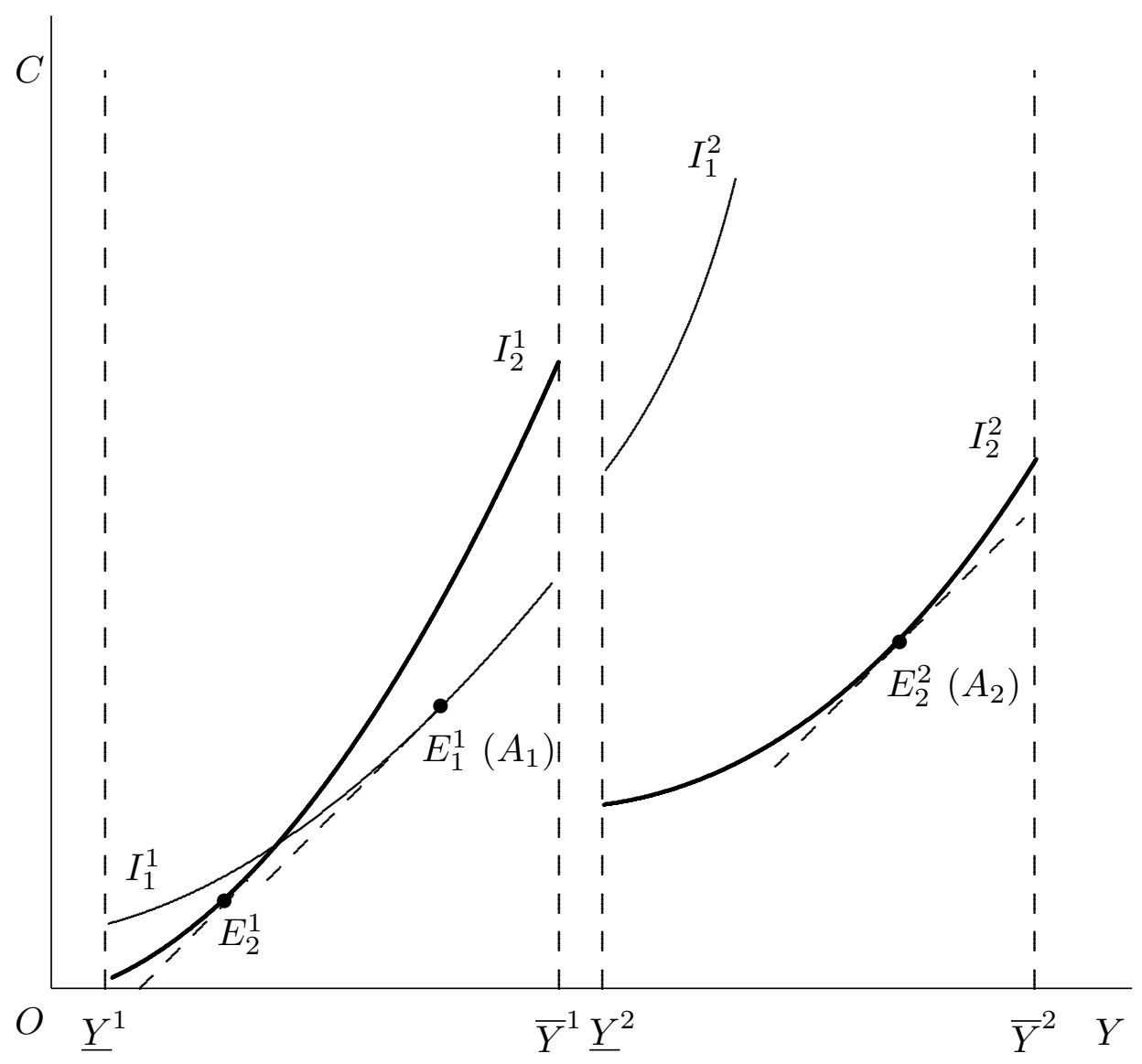

Figure 3

Case (i): A Fully Revealing Optimum 


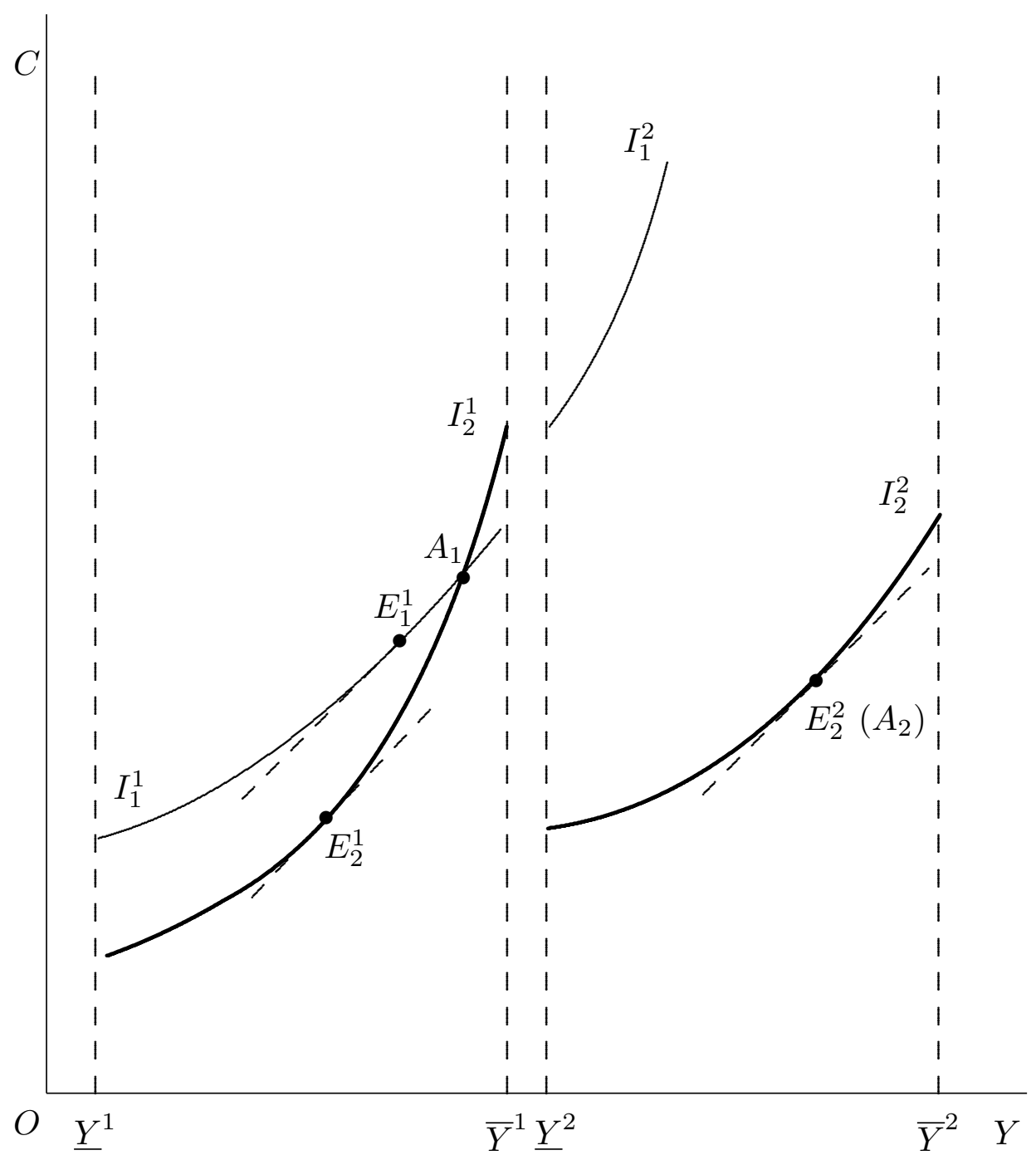

Figure 4

Case (i): An Interior Optimum 


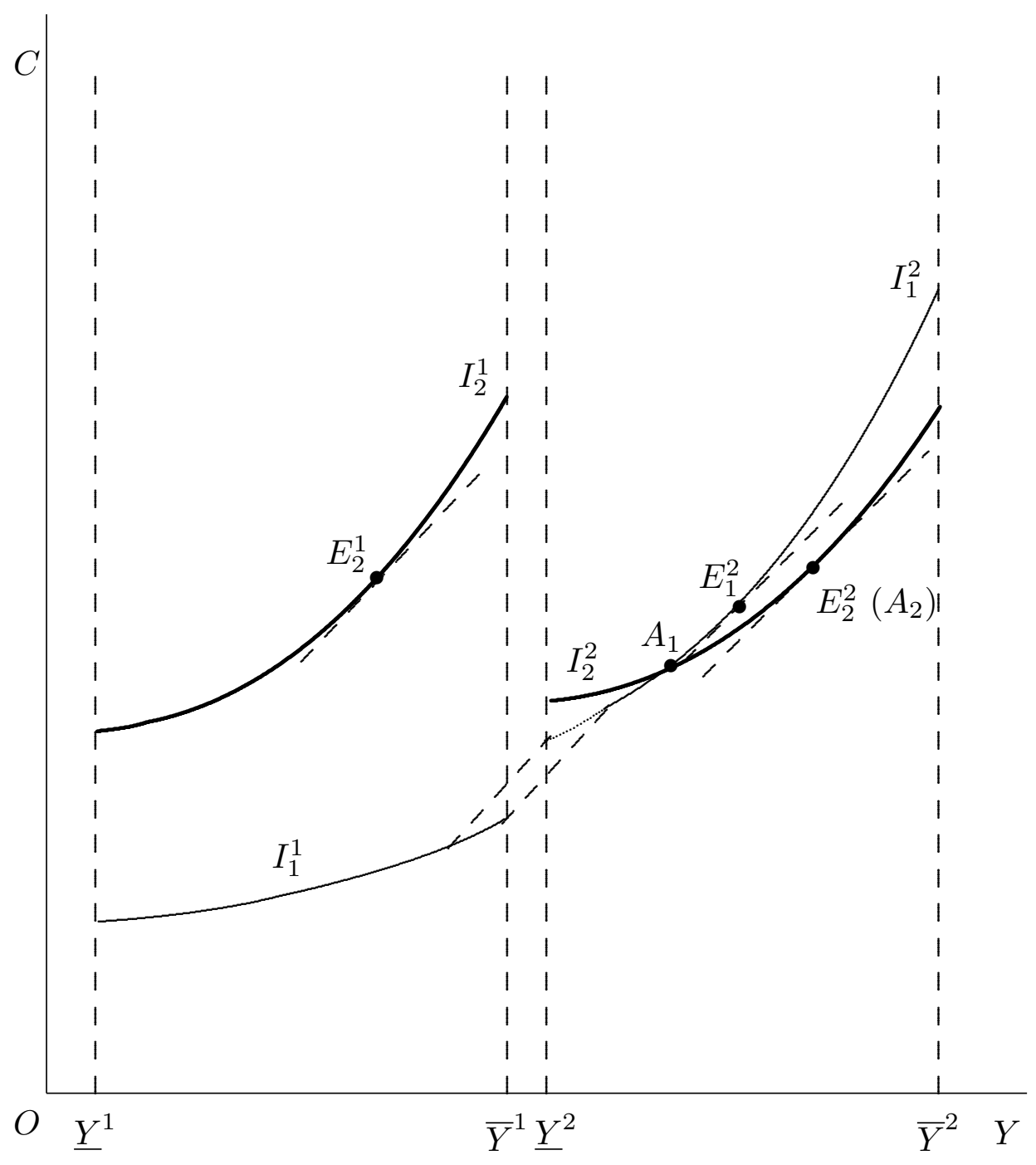

Figure 5

Case (ii): Both Workers in Job 2 


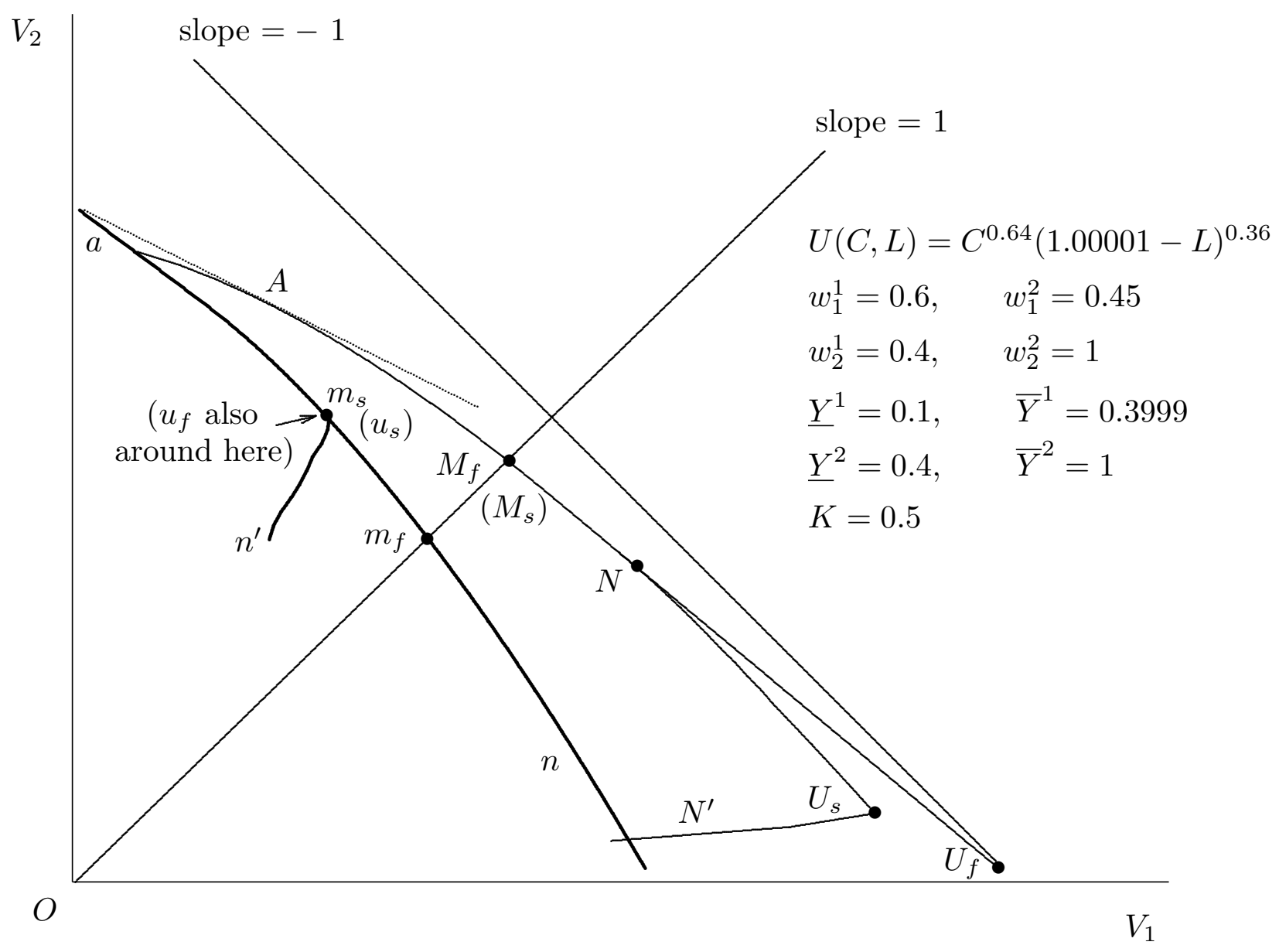

$A M_{f} N U_{f}$ : first-best, Case (i) UPF; $A M_{s} N U_{s} N^{\prime}$ : second-best, Case (i) UPF

$a m_{f} n$ : first-best, Case (ii) UPF; $a m_{s} n^{\prime}$ : second-best, Case (ii) UPF

$U_{f}, u_{f} / U_{s}, u_{s}:$ first-/second-best utilitarian outcome

$M_{f}, m_{f} / M_{s}, m_{s}:$ first-/second-best maximin outcomes

(|slope| of $a m_{f} n$ around $45^{\circ}$ line greater than 1 , due to lower income bound of job 2)

Figure 6

First- and Second-Best UPF's in Case (i) and Case (ii) 


\section{References}

Beaudry, Paul, Charles Blackorby, and Dezso Szalay (2009), 'Taxes and Employment Subsidies in Optimal Redistribution Programs', American Economic Review 99, 216-242.

Boadway, Robin, Maurice Marchand, Pierre Pestieau, and Maria Del Mar Racionero (2002), 'Optimal Redistribution with Heterogeneous Preferences for Leisure', Journal of Public Economic Theory 4, 475-98.

Boadway, Robin, Zhen Song, and Jean-François Tremblay (2013), 'Optimal Income Taxation and Job Choice', mimeo.

Choné, Philippe and Guy Laroque (2010), 'Negative Marginal Tax Rates and Heterogeneity', American Economic Review, 100, 2532-47.

Diamond, Peter (1980), 'Income Taxation with Fixed Hours of Work', Journal of Public Economics 13, 101-110.

Diamond, Peter (2006), 'Optimal Tax Treatment of Private Contributions for Public Goods with and without Warm Glow Preferences', Journal of Public Economics 90, 897-919.

Ebert, Udo (1992), 'A Reexamination of the Optimal Nonlinear Income Tax', Journal of Public Economics 49, 47-73.

Guesnerie, Roger and Jesus Seade (1982), 'Nonlinear Pricing in a Finite Economy', Journal of Public Economics 17, 157-179.

Hellwig, Martin F. (2007), 'A Contribution to the Theory of Optimal Utilitarian Income Taxation', Journal of Public Economics 91, 1449-1477.

Homburg, Stefan (2002), 'The Optimal Income Tax: Restatement and Extensions', Finanzarchiv: Public Finance Analysis 58, 363-395.

Jacquet, Laurence, Etienne Lehmann, and Bruno Van der Linden (2013), 'Optimal Redistributive Taxation with both Extensive and Intensive Responses', Journal of Economic Theory, forthcoming.

Krause, Alan (2009), 'Optimal Nonlinear Income Taxation with Learning-by-Doing', Journal of Public Economics 93, 1098-1110. 
Matthews, Steven and John Moore (1987), 'Monopoly Provision of Quality and Warranties: An Exploration in the Theory of Multidimensional Screening', Econometrica 55, 441467.

Mirrlees, James A. (1971), 'An Exploration in the Theory of Optimum Income Taxation', The Review of Economic Studies 38, 175-208.

Saez, Emmanuel (2002), 'Optimal Income Transfer Programs: Intensive versus Extensive Labor Supply Responses', The Quarterly Journal of Economics, 117, 1039-1073.

Stern, Nicholas H. (1982), 'Optimum Taxation with Errors in Administration', Journal of Public Economics 17, 181-211.

Stiglitz, Joseph E. (1982), 'Self-Selection and Pareto Efficient Taxation', Journal of Public Economics 17, 213-240.

Tuomala, Matti (1990), Optimal Income Tax and Redistribution, Oxford: Clarendon Press. Weymark, John A. (1986), 'A Reduced-Form Optimal Nonlinear Income Tax Problem', Journal of Public Economics 30, 199-217. 